\title{
Determinan Pembiayaan UMKM di Indonesia Tahun 2011-2015: Pendekatan Generalized Method Of Moment (GMM)
}

\author{
Sagitaria Saputri \\ Muhammad Ghafur Wibowo
}

Fakultas Ekonomi dan Bisnis Islam

Universitas Islam Negeri Sunan Kalijaga Yogyakarta

Email: gus_fur2001@yahoo.com

\begin{abstract}
Abstrak
Penelitian ini mengidentifikasikan mengenai faktor pembiayaan yang menjadi isu penting pertumbuhan UMKM. Pembiayaan yang disalurkan setiap provinsi belum merata dan masih adanya gap. Sedangkan permodalan UMKM begitu penting dalam mengatasi kemiskinan, mengurangi pengangguran serta meningkatkan pertumbuhan ekonomi. Metode yang digunakan dalam penelitian ini adalah analisis generalized method of moment (GMM) Arellano Bond dengan periode penelitian dari Januari 2011 hingga Juni 2015. Dari hasil analisis GMM Arellano Bond dapat disimpulkan bahwa variabel internal perbankan syariah DPK dan NPF memiliki pengaruh negatif signifikan terhadap pembiayaan UMKM. Sedangkan FDR memberi dampak positif signifikan terhadap pembiayaan UMKM. Kemudian variabel makroekonomi berupa IPI memberikan dampak positif signifikan terhadap pembiayaan UMKM. Penelitian ini merekomendasikan pentingnya peningkatan proporsi pembiayaan UMKM dengan mengoptimalkan dana pihak ketiga untuk ditempatkan pada sektor riil.
\end{abstract}

Kata Kunci: Usaha Mikro Kecil dan Menengah (UMKM), perbankan syariah, GMM Arellano-Bond

\begin{abstract}
This research identifies the financing factor that is still an important issue of SMEs survival. The financing distributed by each province is not evenly distributed and there is existing gap. While the capital of SMEs is so important in overcome poverty and unemploymentas well as in increasing theeconomic growth. The purpose of this research is to know the impact of internal variables of Islamic banking in the form of Third Party Fund (DPK), Financing to Deposit Ratio (FDR) and Non Performing Financing (NPF) and external variable of Islamic banking from Industrial Production Index (IPI) to SMEs financing. The method reference is Arellano Bond's generalized method of moment (GMM) analysis with the research period from January 2011 to June 2015. The objects of the research are five provinces with the largest SMEs financing in Indonesia. From the analysis of GMM Arellano Bond, it can be concluded those internal variables of Islamic bankingare $N P F$ and DPK have a negative significant impact on SMEs financing. While the FDR gives a positive significant impact on the SMEs financing. Then macroeconomic variable in the form of IPI give positive significant impact to SMEs financing. This study recommends the importance of increasing the proportion of SMEs financing by optimizing third party funds to be placed on the real sector.
\end{abstract}

Keywords:Small and Medium entreprises (SMEs), islamic banking, GMM Arellano Bond 


\section{Pendahuluan}

Kontribusi Usaha Mikro Kecil danMenengah (UMKM) dalam perekonomian Indonesia ditunjukan oleh populasinya sebagai pelaku usaha terbesar, menjadi pilar perekonomian yang tangguh. Hal ini dibuktikan pada saat terjadi krisis 1997/1998 sektor UMKM mampu bertahan dari goncangan perekonomian dunia. ${ }^{1}$ Kontribusi lainnya dalam penyerapan tenaga kerja dan pembentukan Produk Domestik Bruto (PDB), kontribusi terhadap PDB dapat dijelaskan dalam grafik berikut:

Grafik 1. Kontribusi UMKM terhadap PDB Tahun 1997-2013

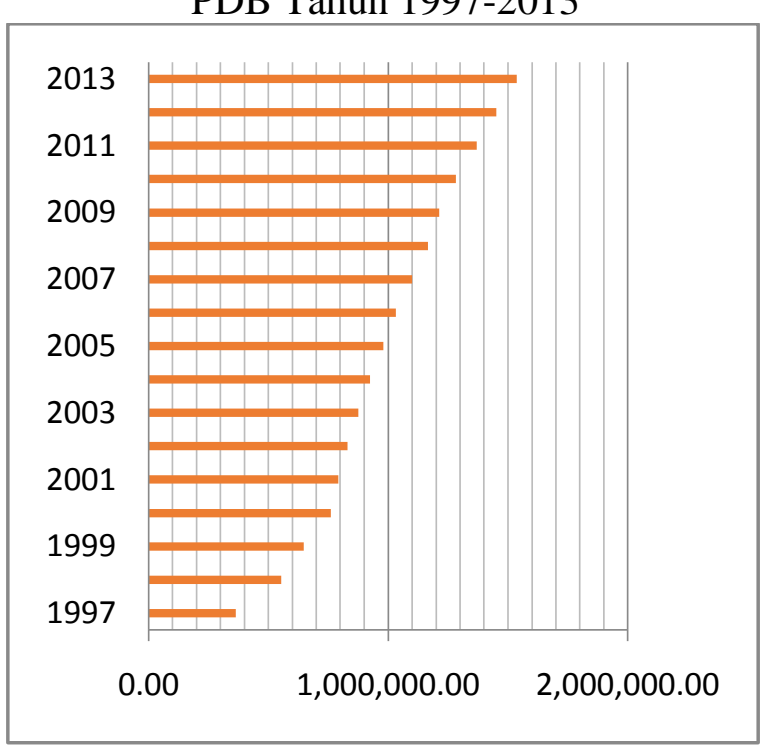

Sumber: Badan Pusat Statistik, 2016

Berdasarkan data BPS (2016) mengenai perkembangan UMKM bahwa kontribusi UMKM terhadap PDB mengalami tren peningkatan sejak tahun 1997 hingga tahun 2013. Pada tahun 1997 sebesar Rp363.200,44 miliar hingga pada tahun 2013 mencapai Rp1.536.918,80 miliar.

Di samping itu, kontribusi UMKM juga terlihat dominan dari sisi banyaknya unit usaha yang terserap dalam UMKM. Berdasarkan data publikasi Kementrian Koperasi dan UMKM Republik Indonesia (2017:1), jumlah unit usaha UMKM mencapai 57.900,787 (99,99 persen) pada

\footnotetext{
1 Kara, Muslimin. (2013). Kontribusi Pembiayaan Perbankan Syariah terhadap Pengembangan Usaha Mikro, Kecil dan Menengah. Jurnal Ahkam Vol. VIII No. 2, Juli 2013
}

tahun 2013. Sedangkan 5.066 (0,1 persen) merupakan unit Usaha Besar (UB) dengan sumbangan tiga sektor terbesar mencapai 85 persen yakni berupa pertanian, perdagangan dan jasa. Selain itu, UMKM turut berperan besar dalam penyerapan tenaga kerja secara nasional. Jumlah tenaga kerja yang terserap oleh UMKM pada tahun 2013 mencapai 114.144.082 tenaga kerja atau 96,99 persen dan sebesar 3.537.162 atau 3,01 persen disumbang dari UB.

Namun faktanya UMKM sempat mengalami kendala pada tahun 2010, sekitar 57 persen UMKM yang ada di Indonesia mengalami kesulitan dalam menjalankan usahanya. Kesulitan utama yang dihadapi pelaku usaha adalah kesulitan permodalan yaitu sebesar 31,11 persen, kesulitan bahan baku sebesar 24,80 persen, dan kesulitan pemasaran sebesar 24,60 persen $^{2}$. Dari data tersebut dapat dilihat bahwa kendala yang paling besar yaitu kesulitan para pelaku UMKM dalam mendapatkan modal.

Salah satu penyebab kesulitan modal tersebut adalah tingkat suku bunga kredit yang tinggi dan diharuskan ada jaminan kebendaan. ${ }^{3}$ Selain itu, prinsip kehati-hatian yang harus dipegang oleh bank menjadi salah satu alasan mengapa bank mengeluarkan sedikit dana untuk penyaluran kredit, sehingga pebisnis terbagi menjadi dua, bankable dan non-bankable. Sebagian besar UMKM masuk kategori yang kedua ini (Antonio, 2010:51).

Menurut Nurhidayah (2016:43), persoalan lain yang muncul selain modal kerja berupa kesulitan investasi, pemasaran, distribusi dan pengadaan bahan baku serta input lainnya, keterbatasan akses informasi mengenai peluang pasar, keterbatan SDM berkualitas, biaya tinggi akibat prosedur administrasi dan birokrasi yang kompleks. Berdasarkan persoalan ini mengakibatkan terjadinya gap total ekspor antara UMKM dan UB seperti dalam grafik berikut:

\footnotetext{
${ }^{2}$ www.bi.go.id diakses pada tanggal 05

November 2017

${ }^{3}$ Ibid
} 
Grafik 2. Perbandingan Ekspor UMKM dan UB di Indonesia Tahun 20122013

\begin{tabular}{|c|c|c|}
\hline \multirow{3}{*}{$\begin{array}{l}1,400,000.00 \\
1,200,000.00\end{array}$} & & \\
\hline & $1,018,76$ & 979,214 . \\
\hline & \multicolumn{2}{|c|}{$1,000,000.00$} \\
\hline \\
\hline \multicolumn{3}{|l|}{$600,000.00$} \\
\hline \multirow{2}{*}{$\begin{array}{l}400,000.00 \\
200,000.00\end{array}$} & & \\
\hline & $166,625$. & $182,112$. \\
\hline \multirow[t]{2}{*}{0.00} & 50 & \\
\hline & 2012 & 2013 \\
\hline
\end{tabular}

Sumber: Kementerian Koperasi dan UMKM Republik Indonesia, 2017

Berdasarkan data publikasi tersebut dapat dilihat secara jelas adanya gap ekspor UMKM dan UB. Pada tahun 2013 jumlah ekspor UB mencapai Rp979.214,8 miliar atau 84,32 persen, sedangkan nilai ekspor UMKM tahun 2013 hanya Rp182.112,7 miliar atau 15,68 persen. Oleh karena itu adanya akses permodalan bagi UMKM perlu diperhatikan untuk mendukung kontribusi ekspor UMKM terhadap perekonomian nasional.

Melihat kendala yang ada, bank sentral mengeluarkan Peraturan Bank Indonesia (PBI) No. 14/22/PBI/2012 tentang pemberian kredit oleh bank umum dan bantuan teknis dalam rangka pengembangan Usaha Mikro, Kecil, dan Menengah (UMKM) dengan ketentuan pemberian plafon pembiayaan UMKM sebagai berikut:

Tabel 1. Presentase Plafon Pembiayaan UMKM Tahun 2013-2018

\begin{tabular}{|c|c|}
\hline Tahun & $\begin{array}{l}\text { Presentase Plafon Pembiayaan } \\
\text { UMKM }\end{array}$ \\
\hline 2013 & Sesuai kemampuan bank \\
\hline 2014 & Sesuai kemampuan bank \\
\hline 2015 & $\begin{array}{l}\text { Sekurang-kurangnya } 5 \text { persen } \\
\text { dari total pembiayaan }\end{array}$ \\
\hline 2016 & $\begin{array}{l}\text { Sekurang-kurangnya } 10 \text { persen } \\
\text { dari total pembiayaan }\end{array}$ \\
\hline 2017 & $\begin{array}{l}\text { Sekurang-kurangnya } 15 \text { persen } \\
\text { dari total pembiayaan }\end{array}$ \\
\hline 2018 & $\begin{array}{l}\text { Sekurang-kurangnya } 20 \text { persen } \\
\text { dari total pembiayaan }\end{array}$ \\
\hline
\end{tabular}

Sumber: PBI No. 14/22/PBI/2012
Dapat dilihat pada tabel bahwa pada tahun 2013 dan 2014 persentase plafon pembiayaan UMKM sesuai dengan kemampuan bank. Kemudian pada tahun 2015 menjadi 5 persen dari total pembiayaan. Tahun 2016 naik menjadi 10 persen dari total pembiayaan hingga tahun 2018 menjadi 20 persen dari total pembiayaan. Wujud nyata untuk membantu perkembangan UMKM adalah dengan memperbanyak mengoperasikan lembaga keuangan berprinsip bagi hasil, yaitu dengan mendirikan Bank Umum Syariah, Bank Pembiayaan Rakyat Syariah, dan Baitul Mal Wa Tamwil. ${ }^{4}$

Perlunya akses permodalan untuk mendorong perkembangan UMKM begitu penting. Sehingga pentingnya permodalan bagi sektor UMKM diharapkan dapat mengurangi kemiskinan dan pengangguran, pertumbuhan ekonomi, berkurangnya kesenjangan antar daerah, meningkatnya kualitas manusia, membaiknya mutu lingkungan hidup serta meningkatkan dukungan infrastruktur (Suarja, 2007:2).

Disisi lain, Said (2007:1) mengatakan bahwa ada tiga alasan perlunya modal bagi UMKM. Pertama, sebagian besar pelaku ekonomi di daerah adalah UMKM. Kedua, UMKM adalah kekuatan rakyat yang efektif dalam menanggulangi kemiskinan. Terakhir isu UMKM adalah isu global, bukan lagi isu nasional apalagi lokal. Sehingga salah satu faktor yang perlu dibantu bagi UMKM adalah akses permodalan. Tepatnya, bagaimana mereka mendapatkan modal pada waktunya dengan harga yang wajar.

Perkembangan UMKM yang ada dapat dilihat dari pembiayaan UMKM paling banyak disalurkan pada sebagian besar Pulau Jawa dan Sumatera Utara, hal ini dilihat bahwa lima provinsi dengan pembiayaan terbesar terdiri dari Provinsi DKI Jakarta, Jawa Barat, Jawa Timur, Sumatera Utara dan Jawa Tengah. Berikut disajikan tabel jumlah pembiayaan UMKM ditinjau dari urutan provinsi di Indonesia dengan pembiayaan UMKM terbesar:

\footnotetext{
${ }^{4}$ Muhammad. (2002). Manajemen Bank Syariah. Yogyakarta: UPP AMP YKPN
} 
Tabel 2. Perbandingan jumlah pembiayaan terbesarUMKM di 10 provinsi

\begin{tabular}{llcccc}
\hline \multirow{2}{*}{ No. } & \multicolumn{1}{c}{ Provinsi } & \multicolumn{4}{c}{ Rata-rata Pembiayaan UMKM $($ Rp. Miliar) } \\
\cline { 3 - 6 } & & 2011 & 2012 & 2013 & 2014 \\
1. & DKI Jakarta & 24.893 & 32.107 & 45.045 & 42.739 \\
\hline 2. & Jawa Barat & 6.470 & 8.356 & 10.177 & 10.524 \\
\hline 3. & Jawa Timur & 5.905 & 7.572 & 8.976 & 10.151 \\
\hline 4. & Sumatera Utara & 4.192 & 6.028 & 7.560 & 7.622 \\
\hline 5. & Jawa Tengah & 3.770 & 4.938 & 5.817 & 6.524 \\
\hline 6. & Banten & 1.702 & 1.955 & 2.742 & 2.563 \\
\hline 7. & Aceh & 1.646 & 1.851 & 1.973 & 1.040 \\
\hline 8. & Sumatera Barat & 1.624 & 1.881 & 1.623 & 1.322 \\
\hline 9. & Kalimantan & 1.608 & 1.769 & 2.339 & 1.996 \\
& Timur & & & & \\
10. & Sulawesi Selatan & 1.531 & 1.938 & 2.215 & 2.155 \\
\hline
\end{tabular}

Sumber: Statistik Perbankan Syariah, 20112014

Dari tabel tersebut dapat dilihat bahwa pembiayaan terhadap UMKM tertinggi konsisten ada di Provinsi DKI Jakarta mulai pada tahun 2011 hingga 2014 sebesar Rp24.893 miliar dan mengalami kenaikan menjadi Rp42.739 miliar. Tertinggi kedua ada di Jawa Barat sebesar Rp6.470 miliar pada tahun 2011 dan mengalami peningkatan tahun 2014 sebesar Rp10.524 miliar, ketiga Jawa Timur pada tahun 2014 sebesar Rp10.151 miliar. Selanjutnya Sumatera Utara dengan jumlah pembiayaan pada tahun 2014 sebesar Rp7.622 miliar dan terakhir Provinsi Jawa Tengah sebesar Rp6.524 miliar pada tahun 2014. Kemudian Provinsi Banten hingga Sulawesi Selatan nilai pembiayaan dari tahun ketahun berfluktuatif, sehingga urutannya tidak menentu.

Dengan adanya pembiayaan yang disalurkan pada lima provinsi dengan pembiayaan terbesar tersebut diharapkan mampu meningkatkan produktivitas UMKM. Apabila produktivitas UMKM meningkat, maka kontribusi terhadap PDB juga akan meningkat. Dengan demikian pertumbuhan ekonomi yang diukur dari Indeks Produksi Industri (IPI) juga akan meningkat, karena didukung oleh sektor riil berupa UMKM yang terus meningkatkan produktivitanya.

Kinerja bank syariah selama ini menunjukkan tersalurnya dana yang dihimpun dari masyarakat kepada usaha yang membutuhkan dana. Data yang dirilis Bank Indonesia selalu menunjukan bahwa rasio pembiayaan yang disalurkan perbankan syariah terhadap DPK (Dana Pihak Ketiga) atau FDR (Financing to Deposit Ratio) selalu berkisar diangka seratus persen bahkan lebih. Hal ini berarti, fungsi intermediasi yang dijalankan perbankan syariah berjalan dengan baik.

Permasalahannya menurut Antonio (2010:53), dana yang dihimpun oleh lembaga keuangan syariah begitu jauh berbeda dibanding dengan total aset perbankan nasional. Hingga saat ini rasio aset perbankan syariah terhadap total aset perbankan nasional belum mencapai dua persen. Artinya, meskipun FDR-nya tinggi namun karena angkanya masih sangat kecil, maka pengaruhnya terhadap perekonomian nasional belum begitu terasa.

$$
\text { Penelitian Yasmin }
$$

menemukan bahwaDPK, FDR, inflasi dan IPI berpengaruh positif terhadap pembiayaan UKM. Sedangkan NPF, Equivalent Rate Pembiayaan (ERP), dan Bonus Sertifikat Bank Indonesia Syariah (BSBIS) berpengaruh negatif terhadap pembiayaan UKM. Sedangkan Maula dan Khodijah (2008)menemukanbahwa DPK dan NPF berpengaruh tidak positif terhadap pembiayaan murabahah

Penelitian lain oleh Nurhidayah dan Ari (2016), inflasi, Produk Domestik Bruto (PDB), dan margin bagi hasil tidak berpengaruh signifikan terhadap pembiayaan UKM yang dilakukan oleh bank syariah. Akan tetapi hanya FDR yang berpengaruh signifikan terhadap pembiayaan UKM yang dilakukan oleh bank syariah.

Pembiayaan UMKM membutuhkan variabel ekonomi lain yang bersifat dinamis. Artinya nilai suatu variabel dipengaruhi oleh nilai variabel lain dan juga nilai variabel yang bersangkutan di masa lalu. Variabel lain berupa makroekonomi yang menjadi faktor eksternal perbankan, salah satunya IPI sebagai proksi pertumbuhan ekonomi. Sedangkan variabel internal perbankan syariah berupa persepsi bank terhadap prospek usaha debitur, rasio keuangan perusahaan perbankan syariah seperti jumlah kredit macet (NPF), Dana Pihak Ketiga (DPK) dan Financing to Deposit Ratio (FDR). 


\section{Pembahasan}

Jenis data yang digunakan dalam penelitian ini adalah data sekunder berupa bulanan dari Januari 2011 sampai dengan Juni 2015 yang mencakup lima provinsi dengan pembiayaan UMKM terbesar di Indonesia. Dalam pengujian statistik dan ekonometrika, penelitian ini menggunakan observasi dengan data panel atau dapat dikatakan bahwa pengamatan yang dilakukan adalah bersifat antar unit dan antar waktu sehingga penanganan model penelitian ini hasilnya menjadi lebih spesifik (Sugiharto, 2012: 44).

Terdapat beberapa variabel yang mempengaruhi pembiayaan UMKM pada lima provinsi dengan pembiayaan UMKM terbesar yakni DKI Jakarta, Jawa Barat, Jawa Timur, Sumatera Utara dan Jawa Tengah. Persamaan dijelaskan dalam model estimasi data panel. Model estimasi data panel sebagai berikut:

$$
P U M K M_{i t}=\beta_{0 i t}+\beta_{1} D P K_{i t}+\beta_{2} F D R_{i t}+\beta_{3} N P F_{i t}+\beta_{4} I P I_{i t}+\varepsilon_{i t}
$$

Dimana:

$\begin{array}{ll}\mathrm{i} & : \text { cross section } \\ \mathrm{t} & : \text { time series } \\ \beta_{0 i t} & : \text { intersep } \\ \beta_{\mathrm{n}}\left(\beta_{1}, \beta_{2}, \beta_{3}, \beta_{4}\right) & : \text { koefisien variabel independen (DPK, FDR, NPF dan IPI) } \\ \mathrm{DPK} & : \text { Dana Pihak Ketiga } \\ \mathrm{FDR} & : \text { Financing to Deposit Ratio } \\ \mathrm{NPF} & : \text { Non Performing Financing } \\ \mathrm{IPI} & : \text { Indeks Produksi Industri } \\ \varepsilon_{\mathrm{it}} & : \text { error }\end{array}$

Metode yang akan digunakan dalam penelitian ini adalah regresi data panel dinamis dengan menggunakan pendekatan generalized method of moment (GMM) Arellano-Bond. Berikut ditampilkan bagan tahapan regresi dalam penelitian ini:

Bagan 1.Tahapan Regresi GMM Arellano Bond

Analisis karakteristik dan gambaran umum variabel

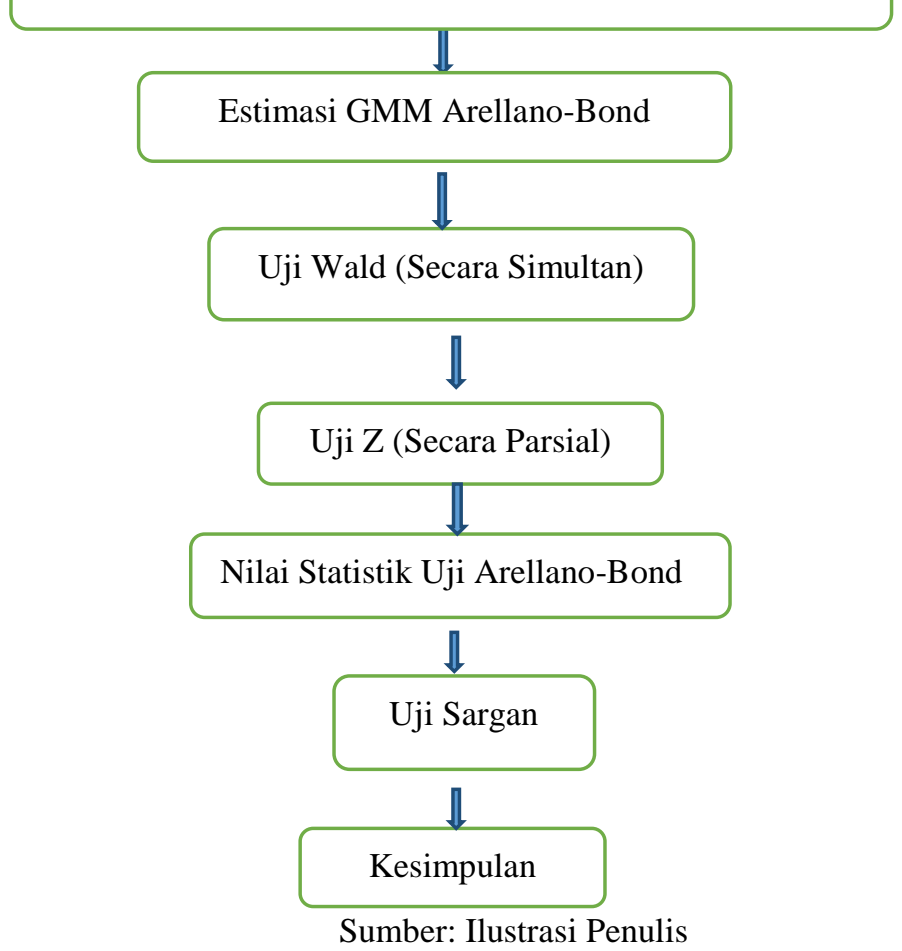


Pencarian model terbaik dalam menganalisis fenomena ekonomi yang dilakukan oleh para ekonom yang telah berkembang cukup pesat saat ini dengan menggunakan data panel. Selanjutnya analisis data panel dapat digunakan pada model yang bersifat dinamis. Dimana variabel dependen tidak hanya tergantung dari variabel eksogen saja, tetapi juga dari lag variabel dependen (Dasril, 2015: 10).

Menurut Nabilah (2016:205), penelitian menggunakan regresi data panel dinamis di luar negeri sudah banyak berkembang, namun di Indonesia masih terbatas. Metode ini digunakan karena dapat membentuk model yang tepat untuk menganalisis pembiayaan terhadap UMKM di Indonesia. Keunggulan metode ini adalah dapat mengetahui efek jangka pendek dan efek jangka panjang.

Penyertaan lag variabel dependen ke dalam variabel independen memberikan perbedaan dalam penduga model. Pada regresi data panel statis baik pada model Pooled Least Square (PLS), Fixed Effects Model (FEM), dan Random Effects Model (REM) pendugaan dengan kuadrat terkecil menunjukan efisiensi dan konsistensi. Pada data panel dinamis $y_{i t}$ merupakan fungsi dari $\mu_{i}$ maka $y_{i t-1}$ juga merupakan fungsi dari $\mu_{i}$, sehingga pendugaan dengan kuadrat terkecil akan menghasilkan penduga yang bias dan tidak konsisten meskipun $y_{i}$ tidak berkorelasi secara serial (Baltagi, 2005).

Untuk

ketidakkonsistenan tersebut, menurut Aderson dan Hsiao (1982) dalam Syahrul (2011: 58), dapat digunakan metode estimasi Instrumental Variabel (IV), yakni dengan menginstrumenkan variabel yang berkorelasi dengan error. Baltagi (2005: 136) mengatakan bahwa hasil estimasi Instrumental Variabel Anderson dan Hsiao menghasilkan variasi yang lebih besar dibandingkan GMM Arellano dan Bond. Dengan demikian, hasil estimasi GMM Arellano dan Bond lebih efisien dibandingkan Instrumental Variabel Metode estimasi GMM ArellanoBond menghasilkan estimasi tidak bias,
Anderson dan Hsiao. Sehingga metode Instrumental Variabel Anderson dan Hsiao menghasilkan taksiran yang tak bias, konsisten, namun tidak efisien.

Sedangkan pada estimasi parameter menggunakan metode GMM Arellano dan Bond menggunakan prinsip GMM untuk mendapatkan taksiran yang konsisten (Ibnu Sina, 2016:148). Estimasi parameter pada model panel dinamis GMM menghasilkan estimasi paramaeter yang memiliki sifat tak bias, konsisen dan efisien. Pendekatan GMM digunakan dengan dua alasan yang mendasari pertama, GMM merupakan common estimator dan memberikan kerangka yang lebih bermanfaat untuk perbandingan dan penilaian. Kedua, GMM memberikan alternatif yang sederhana terhadap estimator lainnya, terutama terhadap maximum likelihood.

Meskipun pendekatan Arellano dan Bond GMM Estimator sudah efisien, tetapi Blundel dan Bond (1998) menyarankan menggunakan Blundel and Bond GMMSystem Estimator yang diklaim lebih efisien dari estimator sebelumnya. Hal tersebut karena penggunaaan tambahan informasi level yaitu momen kondisi dan matriks variabel instrumen level disamping first difference dengan cara mengkombinasi momen kondisi dan matriks variabel instrumen (first difference dan level). Maka terdapat dua prosedur estimasi dalam kerangka GMM, yaitu First-different GMM (FD-GMM atau AB-GMM) dan System GMM (SYS-GMM) (Lubis dan Setiawan, 2013: 33).

Arellano Bond (1998: 2), pengukuran GMM secara optimal dapat mengeksploitasi semua batasan momen linier yang mengikuti asumsi tidak ada korelasi serial dalam kesalahan, persamaan yang berisi efek individual, lag variabel dependen dan variabel eksogen. Kemudian diusulkan uji korelasi serial berdasarkan residu GMM dan membandingkan dengan uji Sargan. 
konsisten dan efisien. Berikut ini adalah hasil estimasi GMM Arellano-Bond one $\left(\frac{\delta}{\beta}\right)=\left[\left(N^{-1} \sum_{i=1}^{N}\left(\Delta y_{i t-1^{\prime}} \Delta x_{i}\right)^{\prime} Z_{i}\right) w\left(N^{-1} \sum_{i=1}^{N}\left(\Delta y_{i t-1^{\prime}} \Delta x_{i}\right)\right)\right]^{-1}$
$\left[\left(N^{-1} \sum_{i=1}^{N}\left(\Delta y_{i t-1} \Delta x_{i}\right)^{\prime} Z_{i}\right) w\left(N^{-1} \sum_{i=1}^{N} Z_{i}{ }^{\prime} \Delta y_{i}\right)\right]$

Dimana:

$Z_{i}$ : Matriks instrumen yang valid $w$ : Estimasi tidak bias dan konsisten untuk $w \quad\left({ }_{L x L}\right)$ dengan $L$ adalah jumlah variabel instrumen.

Untuk mendapatkan hasil two step estimator dengan cara mensubsitusikan bobot $w$ dengan $\Delta^{-1}$, dengan:

$$
\Delta^{-1}=N^{-1} \sum_{t-1}^{N} z_{i}^{\prime} \Delta v_{i} \Delta v_{i} z_{i}
$$

Sehingga estimasi GMM Arellano Bond menjadi sebagai berikut:

$$
\begin{gathered}
\left(\frac{\delta}{\beta}\right)=\left[\left(N^{-1} \sum_{i=1}^{N}\left(\Delta y_{i t-1^{\prime}} \Delta x_{i}\right)^{\prime} z_{i}\right) \Delta^{-1}\left(N^{-1} \sum_{i=1}^{N}\left(\Delta y_{i t-1^{\prime}} \Delta x_{i}\right)\right)\right]^{-1} \\
{\left[\left(N^{-1} \sum_{i=1}^{N}\left(\Delta y_{i t-1^{\prime}} \Delta x_{i}\right)^{\prime} Z_{i}\right) \Delta^{-1}\left(N^{-1} \sum_{i=1}^{N} Z_{i}{ }^{\prime} \Delta y_{i}\right)\right]}
\end{gathered}
$$

\section{Uji Signifikansi Parameter}

Nabillah (2016: 207), pengujian ini digunakan untuk mengetahui ada tidaknya hubungan di dalam model. Uji Wald digunakan sebagai uji signifikansi model secara serentak (simultan) dalam persamaan (2). Hipotesis dan statistik uji Wald pada persamaan (2).

$H_{0}: \beta_{1}=\beta_{2}=\cdots=\beta_{p}=0$ (Tidak ada koefisien yang signifikan terhadap model)

$\mathrm{H}_{1}$ : Paling tidak ada satu $\beta_{j} \neq 0, j=$ $1,2, \ldots . p$ (Ada minimal satu koefisien yang signifikan terhadap model)

$w=\beta \tilde{\mathrm{V}}^{-1} \beta \sim X^{2}(K)$

Dimana:

$\mathrm{K}$ : Banyaknya variabel independen

Keputusannya adalah $\mathrm{H}_{0}$ ditolak jika nilai statistik uji $\mathrm{W}$ lebih besar dari tabel chi-square $\left(\mathrm{X}^{2}\right)$ atau nilai $p$ value $<\alpha$.

Sedangkan uji $\mathrm{Z}$ digunakan sebagai uji signifikansi model secara parsial karena jumlah observasi yang besar. Hipotesis dan statistik uji Z pada persamaan (3).

$H_{0}: \beta_{j}=0$

$H_{1}: \beta_{j} \neq 0, j=1,2, \ldots p$ step estimator:

$$
Z_{\text {hitung }}=\frac{\beta_{j}}{s e\left(\beta_{j}\right)}
$$

Keputusannya adalah $\mathrm{H}_{0}$ ditolak jika nilai statistik uji $\mathrm{Z}$ lebih besar dari $\mathrm{Z}_{\text {tabel }}$ sebesar 1,96 atau nilai $p$-value $<\alpha$.

\section{Uji Spesifikasi Model}

Uji spesifikasi model yang digunakan adalah uji Arellano-Bond (uji konsistensi) dan uji Sargan (uji validitas instrumen) menurut Nabillah (2016: 207) adalah sebagai berikut:

a. Uji Arellano-Bond

Uji Arellano-Bond digunakan untuk menguji konsistensi estimasi yang diperoleh dari proses GMM. Hipotesis uji Arellano-Bond serta statistik uji pada persamaan (4).

Hipotesis uji Arellano dan Bond adalah sebagai berikut:

$\mathrm{H}_{0}$ : Tidak terdapat autokorelasi pada sisaan first difference orde ke-i

$\mathrm{H}_{1}$ : Terdapat autokorelasi pada sisaan first difference orde ke-i

Berikut adalah persamaan uji Arellano-Bond:

$$
m(2)=\frac{\Delta \tilde{V}_{i, t-2}^{\prime} \Delta \tilde{V} *}{(\Delta \tilde{V}) \frac{1}{2}} \sim N(0,1)
$$

\section{Dimana:}

$\Delta \tilde{V}_{i, t-2}^{\prime}$ : Vektor error pada lag ke-2 dengan orde $q=\sum_{i=1}^{N} T_{i}-4$

$\Delta \tilde{V} * \quad$ : Vektor error yang dipotong untuk menyesuaikan $\Delta \tilde{V}_{i, t-2}^{\prime}$ yang berukuran q x 1

Keputusannya adalah $\mathrm{H}_{0}$ ditolak jika $Z_{\text {hitung }}>Z_{\text {tabel }}$. Hal ini berarti konsisteasi GMM ditunjukan oleh nilai statistik yang tidak signifikan (gagal tolak $\mathrm{H}_{0}$ ) pada $\mathrm{m} 2$.

b. Uji Sargan

Uji Sargan digunakan untuk mengetahui validitas penggunaan variabel instrumen yang jumlahnya melebihi jumlah parameter yang diestimasi (kondisi overidentifying restriction). Hipotesis uji Sargan dan statistik uji pada persamaan (5).

$\mathrm{H}_{0}$ : Kondisi overidentifying restriction dalam estimasi model valid

$\mathrm{H}_{1}$ : Kondisi overidentifying restriction dalam estimasi model tidak valid 
$S=\tilde{V}^{\prime} Z\left(\sum_{i=1}^{N} Z_{i}^{\prime} \tilde{V}_{i} \tilde{V}_{i} Z_{i}\right)^{-1} Z^{\prime} \tilde{\mathrm{V}} \sim X_{L-(k+1)}^{2}$

Dimana:

$\tilde{\mathrm{V}}$ : error dari estimasi model

Keputusannya adalah $\mathrm{H}_{0}$ ditolak jika nilai statistik uji $\mathrm{S}$ lebih besar dari tabel chi-square $\left(\mathrm{X}^{2}\right)$ atau nilai $p$ value $<\alpha$.

\section{Hasil Penelitian}

Estimasi yang digunakan dalam penelitian ini menggunakan GMM ArellanoBond. Hasil pengujian statistik serentak dapat diketahui bahwa nilai $p$-value sebesar 0,000 . Sehingga keputusannya adalah tolak $\mathrm{H} 0$ yang menunjukan bahwa minimal ada satu koefisien yang signifikan terhadap model. Selanjutnya melakukan pengujian signifikansi parameter secara parsial dengan menggunakan software Stata 11 akan dijelaskan pada tabel berikut:

Tabel 3. Hasil Uji Parsial

\begin{tabular}{ccccc}
\hline Prediktor & Koefisien & $\begin{array}{c}\text { Standar } \\
\text { Error }\end{array}$ & $\mathbf{Z}$ & $\begin{array}{c}\boldsymbol{P} \text { - } \\
\text { Value }\end{array}$ \\
\hline PUMKM &, 6309499 &, 050872 & 12,40 & 0,000 \\
DPK &,- 0651985 &, 0322925 & $-2,02$ & 0,043 \\
FDR & 65,94576 & 29,71911 & 2,22 & 0,026 \\
NPF & $-659,6316$ & 219,5086 & $-3,01$ & 0,003 \\
IPI & 123,7546 & 48,68478 & 2,54 & 0,011 \\
Cons & $-12447,47$ & 5417,585 & $-2,30$ & 0,022 \\
Prob. & - & - & - & 0,000 \\
Wald test & & & & \\
\hline
\end{tabular}

Sumber: data diolah oleh penulis

Diuji secara parsial berdasarkan uji z, bahwa pengaruh DPK terhadap PUMKM dapat dilihat pada tabel di atas bahwa nilai probabilitas $P$-Value sebesar 0,043 yang artinya kurang dari 5 persen $(0,05)$. Pada penelitian ini menggunakan nilai $\alpha$ sebesar 5 persen. Hal ini dapat disimpulkan bahwa hipotesis nol ditolak dan hipotesis satu diterima, sehingga secara statistik variabel DPK di Provinsi DKI Jakarta, Jawa Barat, Jawa Timur, Sumatera Utara dan Jawa Tengah berpengaruh signifikan terhadap Pembiayaan UMKM pada Provinsi DKI Jakarta, Jawa Barat, Jawa Timur, Sumatera
Utara dan Jawa Tengah. Sedangkan rifłai koefisien DPK bernilai negatif, hal ini menunjukan bahwa setiap peningkatan DPK Rp10 miliar maka akan menurunkan Pembiayaan UMKM sebesar Rp0,65miliar. Sehingga variabel DPK berpengruh negatif signifikan terhadap Pembiayaan UMKM.

Pengaruh FDR terhadap Pembiayaan UMKM dilihat pada tabel 3 bahwa nilai probabilitas FDR sebesar 0,026 yang kurang dari 5 persen $(0,05)$. Hal ini dapat disimpulkan bahwa hipotesis nol ditolak dan hipotesis satu diterima, sehingga secara statistik variabel FDR di Provinsi DKI Jakarta, Jawa Barat, Jawa Timur, Sumatera Utara dan Jawa Tengah berpengaruh signifikan terhadap Pembiayaan UMKM pada Provinsi DKI Jakarta, Jawa Barat, Jawa Timur, Sumatera Utara dan Jawa Tengah. Sedangkan nilai koefisien FDR bernilai positif, hal ini menunjukan bahwa setiap peningkatan FDR 1 persen maka akan menaikan Pembiayaan UMKM sebesar Rp65,945 miliar. Sehingga variabel FDR berpengaruh positif signifikan terhadap Pembiayaan UMKM.

Pengaruh NPF terhadap Pembiayaan UMKM dilihat pada tabel 3 bahwa nilai probabilitas NPF sebesar 0,003 yang kurang dari 5 persen $(0,05)$. Hal ini dapat disimpulkan bahwa hipotesis nol ditolak dan hipotesis satu diterima, sehingga secara statistik variabel NPF di Provinsi DKI Jakarta, Jawa Barat, Jawa Timur, Sumatera Utara dan Jawa Tengah berpengaruh signifikan terhadap Pembiayaan UMKM pada Provinsi DKI Jakarta, Jawa Barat, Jawa Timur, Sumatera Utara dan Jawa Tengah. Sedangkan nilai koefisien NPF bernilai negatif, hal ini menunjukan bahwa setiap peningkatan NPF 1 persen maka akan menurunkan Pembiayaan UMKM sebesar Rp659,632 miliar. Sehingga variabel NPF berpengruh negatif signifikan terhadap Pembiayaan UMKM.

Pengaruh IPI terhadap Pembiayaan UMKM dilihat pada tabel 3 bahwa nilai probabilitas FDR sebesar 0,011 yang kurang dari 5 persen $(0,05)$. Hal ini dapat disimpulkan bahwa hipotesis nol ditolak dan 
hipotesis satu diterima, sehingga secara statistik variabel FDR di Provinsi DKI Jakarta, Jawa Barat, Jawa Timur, Sumatera Utara dan Jawa Tengah berpengaruh signifikan terhadap Pembiayaan UMKM pada Provinsi DKI Jakarta, Jawa Barat, Jawa Timur, Sumatera Utara dan Jawa Tengah. Sedangkan nilai koefisien IPI bernilai positif, hal ini menunjukan bahwa setiap peningkatan IPI 1 persen maka akan menaikan Pembiayaan UMKM sebesar Rp123,755 miliar. Sehingga variabel DPK berpengruh positif signifikan terhadap Pembiayaan UMKM.

Begitu juga pengujian secara simultan yang dilihat dari Wald test tabel 3 menunjukan probabilitas wald test sebesar 0,000 yang kurang dari 5 persen. Hal ini dapat disimpulkan bahwa hipotesis nol ditolak dan hipotesis satu diterima. Sehingga secara simultan (bersama-sama) variabel DPK, FDR, NPF dan IPI pada Provinsi DKI Jakarta, Jawa Barat, Jawa Timur, Sumatera Utara dan Jawa Tengah berpengaruh signifikan terhadap Pembiayaan UMKM pada Provinsi DKI Jakarta, Jawa Barat, Jawa Timur, Sumatera Utara dan Jawa Tengah.

Setelah melakukan pengujian signifikansi parameter, maka selanjutnya mengukur kriteria model terbaik. Metode panel dinamis dengan menggunakan pendekatan GMM Arellano-Bond dapat dikatakan baik apabila memenuhi kriteria konsisten dan validitas instrumen. Hasil pengujian kriteria model terbaik akan dijelaskan pada tabel berikut:

\begin{tabular}{lc}
\multicolumn{3}{c}{ Tabel 4. Hasil Kriteria Model } \\
\hline $\begin{array}{l}\text { Nilai Statistik } \\
\text { Uji Arellano- } \\
\text { Bond }\end{array}$ & $P$-Value \\
\hline$-1,1047\left(\mathrm{~m}_{1}\right)$ & 0,2693 \\
$1,1487\left(\mathrm{~m}_{2}\right)$ & 0,2507
\end{tabular}

Sumber: data diolah oleh penulis

Berdasarkan tabel 4 dapat diketahui bahwa metode panel dinamis dengan pendekatan GMM Arellano-Bond telah memenuhi kriteria model terbaik secara statistik yaitu konsisten dan variabel instrumen yang digunakan valid. Hasil Arellano-Bond pada $\mathrm{m}_{1}$ menunjukan nilai $p$ value sebesar 0,2693 artinya lebih dari 5persen. Sehingga keputusannya adalah menerima hipotesis satu, estimasi dapat dikatakan konsisten dan tidak terdapat otokorelasi pada eror first difference orde kedua.

Pengujian yang tidak kalah penting adalah melihat valid tidaknya model panel dinamis yang digunakan. Valid tidaknya model panel dinamis dapat dilihat dari probabilitas uji Sargan. Berdasarkan tabel 5 diketahui bahwa probabilitas uji Sargan sebesar 0,7742 sedangkan tingkat signifikansi yang digunakan adalah 5 persen. Dengan demikian, probabilitas uji Sargan $(0,7742)$ lebih besar dari 5 persen $(0,05)$. Kesimpulannya adalah model panel dinamis yang digunakan dalam penelitian ini valid, sehingga model panel dinamis sudah tepat digunakan.

Tabel 5. Uji Sargan

Nilai Statistik Uji Sargan $P$-Value

$231,9388 \quad 0,7742$

Sumber: data diolah oleh penulis

\section{Dampak Dana Pihak Ketiga (DPK) terhadap Pembiayaan UMKM}

Hipotesis pertama $\left(\mathrm{H}_{\mathrm{a} 1}\right)$ adalah Dana Pihak Ketiga (DPK) berpengaruh positif terhadap peningkatan penyaluran pembiayaan UMKM. Hasil uji parsial menunjukan bahwa besarnya DPK sebagaimana terlihat pada tabel 3 terhadap pembiayaan UMKM adalah negatif. Dari hasil tersebut, terdapat perbedaan antara hipotesis dan hasil. Dalam hipotesis menghendaki besarnya DPK akan memiliki efek positif dalam meningkatkan pembiayaan UMKM, namun hasil menunjukan sebaliknya.

Hasil temuan dari Khodijah (2008) bahwa pengaruh DPK yang negatif terhadap pembiayaan murabahah. Kemungkinan besar sumber dana yang digunakan untuk pembiayaan 
murabahah berasal dari modal inti yaitu dana modal sendiri yang berasal dari pemegang saham. Selain itu adanya berbagai hambatan dalam penyaluran pembiayaan terhadap UMKM menyebabkan adanya inklusi keuangan yang bertujuan untuk mengurangi hambatan dan persoalan UMKM dalam mengakses pembiayaan.

Hal ini berarti ketika jumlah DPK pada perbankan syariah meningkat akan menurunkan jumlah pembiayaan yang disalurkan pada sektor UMKM. Menurut Syarif (2016:12), fungsi dana pihak ketiga tidak maksimal, sehingga penyaluran dana pada sektor usaha mikro kecil dan menengah menjadi kurang. Padahal hasil temuannya yang menarik adalah kesamaan hasil analisis VECM, analisa analisis IRF dan Analisis Variance Deceptation yang menegaskan perlunya DPK sebagai pendorong pembiayaan UKM sehingga akan meningkatkan pertumbuhan UKM di Indonesia.

$$
\text { Aldaba }
$$

mengidentifikasikan bahwa keterbatasan UKM dalam mendapatkan suntikan dana dikarenakan rekam jejak yang terbatas, agunan terbatas yang dapat diterima, dan laporan keuangan serta rencana bisnis yang tidak memadai. Dengan demikian bank menolak permintaan keuangan UKM karena sejarah kreditnya buruk, jaminan yang tidak mencukupi, penjualan, arus kas yang tidak memadai dan tipe bisnis yang tidak stabil.

Disamping itu, menurut Rupeika (2014:116) bahwa akses pembiayaan sebagai tantangan dalam eksistensi UMKM menjadi salah satu tantangan utama bagi UMKM untuk menjalankan bisnis di Baltic. Alternatif pembiayaan bagi UMKM sangat penting dalam mendukung perkembangan negara Baltic. Olehkarenaitu, apabila UMKM tidak mendapat akses pembiayaan dari perbankan maka sangat perlu UMKM mendapatkan alternatif pembiayaan dari sumber lain bukan hanya dari perbankan syariah.

Dalam perspektif Islam dianjurkan adanya prinsip amanah. Begitu juga dalam muamalah seperti dijelaskan dalam Q.S Al-Mu'minun ayat 8:

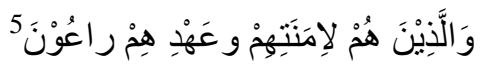

Ayat tersebut menjelaskan bahwa menepati amanah merupakan moral yang mulia, Allah SWT menggambarkannya sebagai orang mukmin yang beruntung (Uswatinnisa, 2011:43). Sebagaimana DPK merupakan dana yang telah dihimpun perbankan syariah yang berasal dari masyarakat. Untuk itu prinsip amanah tersebut begitu penting dalam menjaga kepercayaan masyarakat atas uangnya yang disimpan pada perbankan syariah. Khususnya untuk disalurkan pada sektor UMKM di lima provinsi dengan pembiayaan terbesar di Indonesia.

\section{Dampak Financing To Deposit Ratio (FDR) terhadap Pembiayaan UMKM}

Hipotesis kedua $\left(\mathrm{H}_{\mathrm{a} 2}\right)$ adalah variabel FDR berpengaruh positif terhadap pembiayaan UMKM. Berdasarkan hasil analisis uji parsial GMM Arellano-Bond bahwa FDR memiliki pengaruh positif terhadap pembiayaan UMKM.

Jumlah kredit yang ditentukan perbankan, biasanya melihat terlebih dahulu apakah dana yang sudah terhimpun telah disalurkan secara maksimal atau bahkan belum tersalurkan. Ketika jumlah dana pihak ketiga tersebut tinggi, maka bank akan segera menyalurkan kreditnya. Semakin tinggi rasio FDR yang ada pada perbankan syariah, maka kemampuan perbankan syariah dalam menyalurkan pembiayaan juga tinggi dan meningkat, termasuk pembiayaan terhadap UMKM.

${ }^{5}$ Artinya: "Dan orang-orang yang memelihara amanat-amanat (yang dipikulnya) dan janjinya." 
Hal ini yang menjadi ukuran pada perbankan syariah.

Argumentasi ini sama dengan hasil penelitian Nurhidayah (2016) yang menyatakan bahwa FDR berpengaruh positif dan signifikan terhadap pembiayaan UKM. Disimpulkan bahwa FDR berpengaruh terhadap alokasi pembiayaan UKM hal ini berarti, dalam menyalurkan pembiayaan terhadap UKM pihak bank sangat bergantung dari dana pihak ketiga yang berhasil dihimpun pihak bank. Disamping itu, pihak bank harus memperhatikan alokasi pembiayaan yang diberikan kepada pelaku UKM tidak boleh melebihi dari dana yang berhasil dihimpun perbankan dari pihak ketiga.

Hasil temuan dari Zeneli (2014:130) mengungkapkan bahwa hubungan yang terjalin baik antara perbankan dengan UKM sangat membantu mengurangi biaya pembiayaan, meningkatkan keuntungan kredit, menghindari risiko kredit, dan meningkatkan daya saing UKM.

Pandangan Islam mengenai diperbolehkannya pembiayaan seperti dalam Q.S Al-Baqarah ayat 282 yang artinya "Hai orang-orang yang beriman, apabila kamu bermuamalah tidak secara tunai untuk waktu yang telah ditentukan, hendaklah kamu menuliskannya". Untuk itu dana yang terhimpun dalam perbankan disalurkan kembali kepada masyarakat dalam bentuk pembiayaan. Dengan semakin meningkatnya rasio FDR maka akan meningkatkan jumlah pembiayaan yang disalurkan oleh perbankan khususnya pada sektor UMKM pada lima provinsi dengan pembiayaan terbesar di Indonesia.

\section{Dampak Non Performing Financing(NPF) terhadap Pembiayaan UMKM}

Hipotesis ketiga $\left(\mathrm{H}_{\mathrm{a} 3}\right)$ adalah NPF berpengaruh negatif terhadap penyaluran pembiayaan UMKM. Hasil dari pengolahan uji parsial GMM Arellano-Bond menunjukkan bahwa NPF memiliki pengaruh negatif terhadap pembiayaan UMKM.

Sesuai dengan teori bahwa tingkat NPF yang tinggi mengakibatkan bank mengalami kesulitan dan penurunan tingkat kesehatan bank. Untuk itu perbankan harus menjaga tingkat NPF dalam batasan yang wajar. Bank Indonesia telah menetapkan besaran maksimum NPF pada perbankan adalah lima persen. Apabila nilai suatu bank diatas lima persen, maka bank akan semakin berhati-hati dalam menyalurkan pembiayaan. Sikap kehati-hatian perbankan ini justru akan mengurangi nasabah dalam permintaan pembiayaan, karena proses analisis dan syarat yang semakin rumit (Wardiantika, 2014:158).

Argumen yang sama juga terjadi pada penelitian Iswari (2017) yang memberikan informasi bahwa jumlah NPF berpengaruh negatif terhadap pembiayaan UMKM pada Bank Syariah di Indonesia. Estiyani (2016) dalam temuannya bahwa NPF berpengaruh secara negatif dan signifikan terhadap pembiayaan UKM pada Bank Umum Syariah dan Unit Usaha Syariah di Indonesia. Semakin tinggi NPF yang dimiliki oleh suatu bank maka bank akan lebih berhati-hati dengan mengurangi pembiayaan. Begitu juga ketika nilai NPF meningkat maka perbankan syariah akan mengurangi jumlah pembiayaan yang disalurkan pada sektor UMKM. Hasil penelitian berbeda dilakukan oleh Anastiti (2017), bahwa NPF tidak berpengaruh negatif dan signifikan terhadap pembiayaan UMKM pada BPRS di Indonesia.

NPF sebagaimana dalam kitab shahihain (Bukhari Muslim) bahwa suatu hari Nabi SAW pernah datang ke Madinah dan masyarakat disana melakukan hutang piutang buah-buahan untuk tempo satu tahun, dua tahun sampai tiga tahun. Kemudian Nabi SAW bersabda: Barang siapa yang 
meminjamkan sesuatu, hendaklah ia melakukan takaran dan timbangan yang disepakati dakan waktu yang ditentukan (Abdullah, 2004:561). Sehingga berdasarkan hadis tersebut diperbolehkan adanya kredit dalam jangka waktu yang telah ditentukan dan telah disepakati. Dengan demikian untuk meminimalisir kredit/pembiayaan didasarkan pada hadis tersebut.

\section{Dampak Indeks Produksi Industri(IPI) Pembiayaan UMKM terhadap}

Hipotesis keempat $\left(\mathrm{H}_{\mathrm{a} 4}\right)$ adalah IPI berpengaruh positif terhadap penyaluran pembiayaan UMKM. Hasil dari pengolahan uji parsial GMM Arellano-Bond menunjukan bahwa IPI memiliki pengaruh positif terhadap pembiayaan UMKM.

Alasan yang mendasari adanya pengaruh positif dari IPI sebagai proksi pertumbuhan ekonomi terhadap pembiayaan UMKM adalah secara teori kredit di perbankan termasuk pembiayaanperbankan syariah memiliki hubungan kausalitas dengan pertumbuhan ekonomi. Hubungan ini terjadi karena semakin tinggi pembiayaanyang disalurkan pihak perbankan, maka pertumbuhan ekonomi menjadi salah satu hal yang dapat memacu tumbuhnya sektor yang diberi pembiayaan tersebut. Dalam hal ini, pembiayaandijadikan sebagai penggerak pertumbuhan ekonomi. Sebaliknya, permintaan kredit yang semakin meningkat tersebut terjadi saat pertumbuhan ekonomi sedang tinggi. Jika pertumbuhan ekonomi tidak stabil, permintaan pembiayaanjuga akan lesu (Fauziyyah, 2016:86).

Hasil penemuan ini sejalan dengan Yasmin (2017) menunjukan bahwa dalam jangka panjang hasil estimasi VECM, variabel IPI berpengaruh positif dan signifikan terhadap pembiayaan UKM. Alasannya, ketika pertumbuhan ekonomi membaik yang direfleksikan dengan peningkatan pertumbuhan indeks produksi industri, maka akan mendukung kinerja perbankan syariah termasuk menyalurkan pembiayaan UKM yang menggerakan sektor riil.

Dalam perspektif Islam, bahwa dalam produksi terdapat prinsip keadilan. Sebagaimana dalam Q.S AnNahl (16) ayat 5:

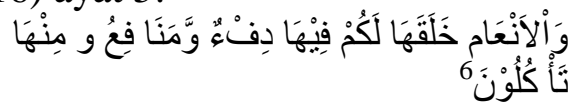

Ayat tersebut menegaskan bahwa dalam Islam produksi begitu penting, karena dengan produksi kebutuhan manusia dapat terpenuhi. Segala yang diciptakan Allah untuk manusia merupakan sumber daya yang harus dimanfaatkan dan dimakmurkan untuk kemaslahatan hidup manusia. Sumber-sumber ekonomi yang ada perlu dijaga dan dilestarikan. Begitu juga IPI dapat menjadi proxy dari pertumbuhan ekonomi.

Sedangkan komitmen Islam yang besar pada persaudaraan dan keadilan, menuntut agar semua sumber daya dimanfaatkan untuk mewujudkan maqashid syariah, yakni pemenuhan kebutuhan hidup manusia, terutama kebutuhan dasar (primer). Persaudaraan dan keadilan juga menuntut agar sumberdaya didistribusikan secara adil kepada seluruh rakyat melalui kebijakan yang adil.

Di samping itu, dikhawatirkan adanya kesenjangan (gap) antara masyarakat yang berpenghasilan menengah ke bawah dan menengah ke atas seperti halnya pada pelaku UMKM dan Usaha Besar. Hal ini sesuai dalam perspektif Ekonomi Syariah untuk meniadakan atau mengurangi adanya kesenjangan dianjurkan untuk

\footnotetext{
${ }^{6}$ Artinya: "Dan Dia telah menciptakan binatang ternak untuk kamu; padanya ada (bulu) yang menghangatkan dan berbagai manfaat, dan sebagianya kamu makan".
} 
mendistribusikan kekayaan kepada masyarakat yang kurang mampu.

Dalam sistem keuangan dan perbankan dirancang secara organis dan terkait satu sama lain untuk memberikan sumbangan yang positif bagi pengurangan ketidakadilan dalam ekonomi dalam bentuk pembiayaan (kredit) bagi masyarakat dan memberikan pinjaman lunak bagi masyarakat ekonomi lemah melalui produk qardhul hasan.

Al-Qur'an dengan tegas mengatakan dalam Q.S Al-Hasyr ayat 59 yang artinya "Supaya harta itu tidak beredar di kalangan orang kaya saja diantara kamu". Karena itu, Islam menekankan keseimbangan antara pertumbuhan dan pemerataan. Untuk itu, keduanya merupakan dua sisi dari sebuah entitas yang tidak dapat dipisahkan.

\section{Penutup}

Berdasarkan hasil penelitian dengan metode GMM Arelanno Bond dan mengacu pada pembahasan yang telah dipaparkan pada uraiansebelumnya maka diperoleh berbagai kesimpulan sebagai berikut:

1. Dana Pihak Ketiga (DPK) memberikan dampak negatif terhadap pembiayaan UMKM pada lima provinsi di Indonesia dengan pembiayaaan terbesar periode 2011-2015. Nilai DPK yang semakin meningkat akan menurunkan total pembiayaan UMKM. Jumlah DPK yang terhimpun kemungkinan dialihkan bukan untuk sektor UMKM. Selain itu bank syariah menolak permintaan permodalan UMKM kemungkinan karena sejarah kreditnya buruk, jaminan yang tidak mencukupi, penjualan dan arus kas yang tidak memadai serta tipe bisnis yang tidak stabil.

2. Financing to Deposit Ratio (FDR) sebagai variabel internal perbankan yang dekat dengan pembiayaan memberikan pengaruh positif terhadap pembiayaan UMKM. Rasio FDR yang semakin tinggi akan mendorong perbankan syariah dalam menyalurkan pembiayaan termasuk pada pembiayaan UMKM pada lima provinsi di Indonesia dengan pembiayaan terbesar.

3. Non Performing Financing (NPF) memiliki pengaruh negatif terhadap pembiayaan UMKM. Nilai NPF yang tinggi akan menurunkan kesehatan perbankan syariah. Dengan besaran maksimum yang ditetapkan oleh Bank Indonesia dapat meminimalisir tingginya nilai NPF. Untuk itu sikap kehati-hatian perbankan syariah dalam menyalurkan pembiayaan terhadap UMKM begitu dipertimbangkan agar dapat mengurangi terjadinya kredit macet.

4. Indeks Produksi Industri (IPI) memiliki pengaruh positif terhadap pembiayaan UMKM. Sehingga kenaikan jumlah pembiayaan yang disalurkan oleh perbankan syariah terhadap sektor UMKM akan menumbuhkan ekonomi disekitarnya.

5. Secara keseluruhan penelitian ini menyimpulkan bahwa semua variabel internal perbankan syariah maupun variabel eksternal perbankan syariah memberikan pengaruh yang signifikan terhadap pembiayaan UMKM pada lima provinsi di Indonesia dengan pembiayaan terbesar.

\section{Daftar Pustaka}

Abdullah bin Muhammad bin Abdurrahman bin Ishaq, Al-Shekh. (2004). Tafsir Ibnu Katsir Jilid 1. (Abdurrahim Mu'thi et. Al: Penerjemah). Bogor: Pustaka Imam Syafi'i

Al-Qur'an. (2002). Al-Qur'an Al-Karim dan Terjemahnya. Semarang: Karya Toha Putra

Adzimatinur, Fauziyyah et.al. (2016). Faktor-faktor yang Mempengaruhi Besaran Pembiayaan Perbankan Syariah di Indonesia. Jurnal Al- 
Muzara'ah ISSN p: 2337-6333; e: $2355-$ 4363

Afandi, Yazid. (2009). Fiqh Muamalah dan Implementasinya dalam Lembaga Keuangan Syariah. Yogyakarta: Logung Pustaka

Alamsyah, Halim. (2015). Pentingnya Keuangan Inklusif dalam Meningkatkan Akses Masyarakat dan UMKM terhadap Fasilitas Jasa Keuangan Syariah. Skripsi UIN Sunan Ampel Surabaya

Aldaba, Rafaelita M. (2012). Small and Medium Enterprises' (SMEs) Access to Finance: Philippines. Discussion Paper Series Februari No. 2012-05

Antonio, Syafi'i. (2001). Bank Syariah: Dari Teori ke Praktik. Jakarta: Gema Insani

Antonio, Syafi'i, Aam S. Rusdiana. (2010). Peran Ekonomi Syari'ah dalam Pembangunan Daerah. Jurnal Multikultural dan Multireligius Vol. IX, No. 33, Januari-Maret 2010

Arellano, M., Bond, S. (1991). Some test of specification for panel data: Monte carlo evidence and an application to employment equations. Review of Economic Studies, 58(2), 277-297

Ascarya. (2008). Akad dan produk Bank Syariah. Jakarta: Raja Grafindo Persada

Ascarya. (2012). Alur Transmisi dan Efektifitas Kebijakan Moneter Ganda di Indonesia. Buletin Ekonomi Moneter dan Perbankan Vol.14, No.3, Januari, ISSN: $1410-8046$

Aziz, Hassanuddeen Abd, dkk. (2014). Factors Determining Islamic Banks' Deposits in Qatar: An Empirical Study. International Journal of Economic Practices and Theories, Vol. 4 No. 6

Baltagi, Badi H. (2005). Econometric Analisis of Panel Data. Third Edition. England: Jhon Wiley and Son Ltd

Bank Indonesia. (2014). Muatan Kebanksentralan. Pusat Riset dan Edukasi Bank Sentral

Bank Indonesia. (2008). UUPS No. 21 Tahun 2008 Tentang Perbankan Syariah dalam Pasal 25
Badan Pusat Statistik. (2016). Tabel Perkembangan UMKM pada Periode 1997-2013

Blundell, R., \& Bond, S. (1998). Initial Conditions and Moment Restrictions in Dynamic Panel Data Models. Journal of Econometrics, Vol. 87, pp.115-143

Darmawan, Deni. (2013). Metode Penelitian Kuantitatif. Bandung: Remaja Rosdakarya Offset

Dasril, Roziana Octia. (2015). Dampak Inklusi Keuangan terhadap Kebijakan Kebijakan Moneter: Pengalaman Empiris dengan Data Panel Dinamis. Skripsi IPB Bogor

Dendawijaya, Lukman. (2009). Manajemen Perbankan. Jakarta: Ghalia Indonesia

Estiyani, Sulis. (2016). Faktor-faktor yang Mempengaruhi Pembiayaan Usaha Kecil dan Menengah (UKM) pada Bank Umum Syariah dan Unit Usaha Syariah di Indonesia. Skripsi UIN Sunan Kalijaga Yogyakarta

Fauziyyah, Neneng Ela. (2016). Analisis Dampak Kebijakan Pelonggaran Financing to Value (FTV) terhadap Penyaluran Pembiayaan Properti di Perbankan Syariah dalam Kerangka Kebijakan Makroprudensial. Skripsi UIN Sunan Kalijaga Yogyakarta

Fitriastuti, Triana. (2015). Implementasi Kuangan Inkluasi Bagi masyarakat Perbatasan (Studi Kasus pada Kutai Timur, Kabupaten Kutai Kartanegaran dan Kota Samarinda, Kalimantan Timur, Indonesia). SNEMA Universitas Negeri Padang

Firmansyah, Irman. (2014). Determinan of Non Performing Loan: The Case of Islamic Bank in Indonesia. Buletin Ekonomi Moneter dan Perbankan Vol. 17 No. 2 Oktober 2014

Ghozali, Imam. (2011). Aplikasi Analisis Multivariate dengan Program IBM SPSS 19 (edisi kelima). Semarang: Universitas Diponegoro

Ibnu Sina, Arya Fendha. (2016). Penerapan 2 SLS GMM-AB pada Persamaan Simultan Data Panel Dinamis untuk Permodelan Pertumbuhan Ekonomi 
Indonesia sebagai Islamic Country. Jurnal Muqtasid Vol. 7 No. 1, Juni 2016 141-162

Irmawati, Setyani. Dkk. (2013). Model Inkluasi Keuangan pada UMKM Berbasis Pedesaan. Journal of Economics and Policy Vol. 6 No. 2 103213

Kara, Muslimin. (2013). Kontribusi Pembiayaan Perbankan Syariah terhadap Pengembangan Usaha Mikro, Kecil dan Menengah. Jurnal Ahkam Vol. VIII No. 2, Juli 2013

Kementrian Koperasi dan UKM Republik Indonesia. (2012). Kriteria UMKM

Kementrian Koperasi dan UKM Republik Indonesia. (2017). Data UMKM

Khodijah H., Maula, (2008). Pengaruh Simpanan (Dana Pihak Ketiga), Modal Sendiri, Margin Keuntungan dan NPF (Non Performing Financing) terhadap Pembiayaan Murabahah pada Bank Syariah Mandiri. Skripsi UIN Sunan Kalijaga

Kuncoro, Mudrajat dan Suharjono. (2002). Manajemen Perbankan, Teori dan Aplikasi, Cet Ke-1. Yogyakarta: BPFE

Kuncoro, Mudrajat. (2007). Catatan tentang Sektor Industri dan UMM 10 tahun Pasca Krisis. Makalah Seminar PSAK

Kuncoro, Mudrajat. (2011). Metode Kuantitatif: Teori dan Aplikasi untuk Bisnis dan Ekonomi. Yogyakarta: STIM YKPN

Lubis, Khairul Andri dan Setiawan. (2013). Penerapan Generalized Method of Moments pada Persamaan Simultan Panel Dinamis pada Permodelan Pertumbuhan Ekonomi di Indonesia. Prosiding Seminar nasional Manajemen Teknologi XIX, Program Studi MMTITS. Surabaya

Muhammad. (2002). Manajemen Bank Syariah. Yogyakarta: UPP AMP YKPN

Nabilah, Dessy, Setiawan. (2016). Pemodelan Pertumbuhan Ekonomi Indonesia Menggunakan Data Panel Dinamis dengan PendekatanGeneralized Method of Moment Arellano-Bond. Jurnal Sains dan Seni ITS Vol. 5 No. 2
Nurhidayah dan Isvandiari Ari. (2016). Faktor Internal dan Faktor Eksternal yang mempengaruhi Alokasi Pembiayan Usaha Kecil. Jurnal JIBEKA Vol. 10 No. $142-48$

Nurjaya, Endang. (2011). Analisis Pengaruh Inflasi, Sertifikat Bank Indonesia Syariah (SBIS), Non Performing Financing (NPF) dan Dana Pihak Ketiga (DPK) terhadap Pembiayaan Murabahah pada Bank Syariah di Indonesia (Periode Januari 2007-Maret 2011).Skripsi UIN Syarif Hidayatullah Jakarta

Otoritas Jasa Keuangan. (2015). Statistik Perbankan Syariah

Ramadhan, Masyitha Mutiara dan Beik Irfan Sauqi. (2013). Analisis Pengaruh Instrumen Moneter Syariah dan Konvensional Terhadap Penyaluran Dana ke Sektor Usaha Mikro Kecil dan Menengah (UMKM) di Indonesia. Jurnal al-Muzara'ah, Vol I, No. 2

Rohmah, N. (2006). Determinants of Islamic Banks Deposits in Indonesia: An ARDL Modelling Approach. Thesis International Islamic University of Malaysia

Rupeika, Ramona dan Apog. (2014). Financing in SMEs: Case of the Baltic States. Procedia: Sosial and Behavioral Science

Said, Adri dan Widjaja, Ika. (2007). Akses Keuangan UMKM: Buku Panduan untuk Membangun Akses Pembiayaan bagi Usaha Menengah, Kecil dan Mikro dalam Konteks Pembangunan Daerah. Jakarta: Subur Printing

Shafiyah, Mas'udi F. (2013). Pengaruh Instrumen Moneter Syariah terhadap Pembiayaan Investasi di PT Bank Muamalat Indonesia, Tbk. Skripsi IPB Bogor

Shihab, M. Quraish. (2005). Tafsir AlMisbah dan Keserasian Al-Qur'an Vol. 1. Jakarta: Lentera Hati

Subagyo dan Djarwanto. (2005). Statistika Induktif Edisi 5. Yogyakarta: BPFE

Sudaryanto, Hanim, Anifatul. (2015). Evaluasi Kesiapan UKM Menyongsong 
Pasar Bebas Asean (Afta 2003): Suatu Analisis Perspektif dan Tinjauan Teoritis.

Sudaryanto, Ragimun, and Rahma Rina Wijayanti. (2013). Strategi pemberdayaan UMKM menghadapi pasar bebas Asean. Jakarta: Pusat Kebijakan Ekonomi Makro. Badan Kebijakan Fiskal. Kementerian Keuangan

Sugiharto, Lea Widowati. (2014). Dinamika PMA dan PMDN di Indonesia sebagai dampak dari Upah Minimum, Inflasi dan PDRB Tahun 2004-2012: PendekatanDynamic Panel Data Model. Jurnal Ekonomi dan Bisnis VOL. XVII No. 3, Desember 2014

Sugiono. (2012). Memahami Penelitian Kualitatif. Bandung: Alfabeta

Suhardjono. (2003). Manajemen Perkreditan Usaha Kecil dan Menengah. Jakarta: UPP AMP YKPN

Suryono, M Alvien. (2016). Analisi Pengaruh Intrumen Moneter Syariah terhadap Pembiayaan UMKM di DIY. Skripsi UIN Sunan Kalijaga Yogyakarta

Syahrul, Syawal. (2011). Penaksiran Parameter Model Regresi Data Panel Dinamis Menggunakan Metode Blundell dan Bond. Skripsi UI Jakarta

Syarif, Ahmad. (2016). The Growth of Islamic Banking and SMEs Financing in Indonesia. Jurnal Human Falah Vol. 3 No. 1 Juni 2016 1-17

Tambunan, Tulus. (2014). Usaha Mikro Kecil dan Menengah di Indonesia: Isuisu Penting. Jakarta: LP3S

Uswatinnisa. (2011). Implementasi Prinsip Amanah dalam Pengelolaan Dana Pihak Ketiga Ditinjau dari Perspektif Ekonomi Islam: Studi pada PT Bank Muamalat Indonesia Tbk. Cabang Pekanbaru. Skripsi UIN Sultan Syarif Kasim Riau
Wangsawidjaja. (2012). Pembiayaan Bank Syariah. Jakarta: PT Gramedia Pustaka Utama

Wardiantika, Lifstin. Kusumaningtias R. (2014). Pengaruh DPK, CAR, NPF, dan SWBI terhadap Pembiayaan Murabahah pada Bank Umum Syariah Tahun 20082012. Jurnal Ilmu Manajemen Vol. 2 No. 4. Oktober 2014

Wibowo, Muh. Ghafur. (2010). UMKM dalam Pusaran Globalisasi Ekonomi (Kajian Kritis Pasca Pemberlakuan ACFTA). Yogyakarta: Fakultas Syariah dan Hukum Press

Widarjono, Agus. (2016). Ekonometrika Pengantar dan Aplikasinya. Yogyakarta: Ekonosia-FEUII

Wijono, Wiloejo Wirjo. (2005). Pemberdayaan Lembaga Keuangan Mikro sebagai Salah Satu Pilar Sistem keuangan Nasional: Upaya Konkrit Memutus Mata Rantai Kemiskinan. Jurnal Kajian Ekonomi dan Keuangan Jakarta Edisi Khusus Desember 2005

Wirdyaningsih, Perwataatmadja, Gemala dan Yeni. (2006). Bank dan Asuransi Islam di Indonesia. Kencana dan Fakultas Hukum UI

Yasmin, Nurkholis. (2017). Pengaruh Faktor Internal dan Eksternal dan Eksternal Perbankan terhadap Pembiayaan Usaha Kecil dan Menengah pada BPRS di Indonesia. Skripsi IPB Bogor

Zaheer, Sajjad. (2013). The Transmission of Monetary Policy Through Conventional and Islamics Banks. Amnsterdam: University of Amnsterdam

Zeneli, Fjona. (2014). Financing SMEs in Flora city, Albania: between game theory and lack of information. Procedia social and behavioral science 